\title{
Transposition of the EU Public Procurement Directives 2014 in Austria
}

\author{
Bernt Elsner $\quad$ Ruth Bittner
}

\begin{abstract}
:
The EU public procurement directives 2014 further advance the European Commission's ambitions to regulate most public procurement at the EU-wide level. The Directives already set out a fairly concrete legal framework for national parliaments regarding public procurement procedures for work, supply and service contracts above the EU-thresholds. The Austrian parliament decided to implement these directives mostly word for word, but at the same time tried to preserve most of the historical developments to the public procurement law that were specific to Austria. In addition to that, the Austrian legislature responded to recent ECJ case law that was established after the EU Directives were published.

The new public procurement code creates legal certainty for both contracting authorities and contractors in several different aspects. However, the interpretation of some provisions will be subject to case law, especially regarding contractual cooperation between contracting authorities.

Concerning contracts not fully regulated by the Directives - such as concessions as well as social and other specific services - the Austrian legislature opted not to regulate them further and leave some flexibility to the contracting authorities.
\end{abstract}

\section{Keywords:}

Austrian public procurement code, changes to contracts, central purchasing bodies, cooperation between contracting authorities, division into lots, e-procurement, ESPD, inhouse exclusion, innovative procurement, MEAT-principle, passenger transport services, public procurement directives 2014, remedies

\section{Introduction}

The EU public procurement directives 2014 (hereafter the "Directives") further advance the European Commission's ambitions to regulate most public procurement at the EU-wide level. New procurement procedures have been introduced, existing rules have been amended, and procurement has been brought under the jurisdiction of the European Court of Justice (ECJ).

The Directives already establish a concrete legal framework for national parliaments regarding public procurement procedures above certain thresholds. Nevertheless, some latitude still remains to account for national specifics.

\section{Background and structure of Austrian public procurement law}

In Austria, public procurement law is regulated at both the federal and provincial level. The public procurement procedure itself is only regulated at the federal level. The nine Austrian provinces are only empowered to regulate legal review procedures. When doing so, however, they follow the federal law - apart from a few small peculiarities. Therefore, when we discuss remedies, in Section 10, we only discuss the federal provisions.

\footnotetext{
${ }^{1}$ Dir 2014/23/EU; Dir 2014/24/EU; Dir 2014/25/EU.
} 
The "new" public procurement law, which implements the Directives, came into force on August $21^{\text {st }}, 2018 .^{2}$ Previously, procurement was regulated by the public procurement code (BVergG 2006) and the public procurement code for security and defense contracts (BVergGVS), which were both operational at the federal level. Now the relevant provisions are split between the public procurement code (BVergG 2018), the public procurement code for concessions (BVergGK 2018), and the old BVergGVS, which remains unchanged.

\section{Cooperation between contracting authorities}

The new public procurement code gives contracting authorities across Europe much greater legal certainty about the types of cooperation within the public sector that are excluded from public procurement law. It clarifies the conditions under which contracting authorities can conclude contracts with each other without having to comply with the requirements of public procurement law. Until the introduction of the EU Directives, this question had been dealt with according to case-law judgments from the European Court of Justice (ECJ) because the conditions for exemption from procurement law in this regard had not been regulated at the EU-level. In Austria, the previous public procurement code already included a provision regarding so-called "in-house exclusion" that dealt with this problem. ${ }^{3}$

The new Austrian public procurement code strictly follows the Directives in the matter of exclusion grounds for cooperation between contracting authorities. Such exclusion grounds can be divided into two categories:

\subsection{In-house exclusion and institutional cooperation}

The ECJ already substantially clarified the conditions necessary for a contracting authority to award a contract (regardless of its value) directly to a legal entity under its control. The conditions for exclusion were satisfied if the contracting authority had an influence on the contractor similar to that on its own departments and the contractor's main activities were performed for the contracting authority that controlled it. ${ }^{4}$

In addition, a contracting authority was also entitled to award a contract directly to a contractor, even if the contracting authority itself did not have sole control over the contractor, as long as all the shares of the contractor were exclusively held by public authorities. ${ }^{5}$ Waste and wastewater associations in Austria often fulfilled this ground for exclusion.

According to the previously applicable case law, the main criterion for this ground to be fulfilled was that no private shareholder (natural person or corporate entity) held any shares in the contractor. ${ }^{6}$ As soon as a private shareholder held even a minor share, this exclusion no longer applied. This criterion has been softened in the new public procurement code, according to which statutory direct private equity investments without decisive influence on the controlled legal entity no longer stand in the way of an in-house award. ${ }^{7}$

The requirement that the contractor's main activities have to be carried out for the controlling authorities is now specified by a precise value limit: from now on, up to $20 \%$ of the contractor's total turnover may be assigned to other entities without losing the in-house privilege. ${ }^{8}$

\footnotetext{
${ }^{2}$ Published in the official law gazette on August 20 $0^{\text {th }}, 2018$ (BGBl I Nr 65/2018).

${ }^{3}$ Art 10 lit 7 BVergG 2006.

${ }^{4}$ ECJ 18.11.1999, C-107/98, Teckal; 13.10.2005, C-458/03, Parking Brixen; 19.4.2007, C-295/05, Asemfo.

${ }^{5}$ ECJ 11.5.2006, C-340/04, Carbotermo; 13.11.2008, C-324/07, Coditel Brabant; 29.11.2012, C-182/11, Econord.

${ }^{6}$ ECJ 11.1.2005, C-26/03, Stadt Halle und RPL Lochau; Even, if the private person was a non-profit organization: 19.6.2014,

C-574/12, Centro Hospitalar.

${ }^{7}$ Art 10 Par 1 Sec 3 lit c BVergG 2018.

${ }^{8}$ Art 10 Par 1 Sec 1 lit b und Sec 3 lit b BVergG 2018.
} 


\subsection{Contractual cooperation}

Recognized by the judiciary but unregulated by law until now, several contracting authorities may cooperate on a contractual basis without interposing a jointly controlled entity. ${ }^{9}$ For example, one municipality may be contracted to take care of snow removal in another municipality if it owns its own snow-clearing vehicles.

The limits and conditions for the fulfillment of this exclusion ground had never been satisfactorily clarified by case-law. According to the new public procurement code this exclusion ground is fulfilled if:

- the aim of the cooperation between the participating contracting authorities is to deliver the public services they are charged with and to achieve common objectives;

- the authorities enter into the cooperative contract solely out of consideration for the public interest; and

- the participating contracting authorities may not account for more than $20 \%$ of the total (domestic) market in the activities covered by the cooperation. ${ }^{10}$

These criteria are helpful guidelines and provide a certain amount of orientation. However, they are still quite unclear, and some uncertainty about their scope remains.

\section{Award of Concessions}

As the media storm of 2013 testifies, many Austrians were deeply concerned that the imminent EU public procurement legislation would force the privatization of the drinking water supply. The previous public procurement act only regulated works- and service-concessions in a rudimentary way. It only set out minimum requirements for service-concessions - for instance, legal remedies granted by public procurement law were not applicable. Moreover, service-concessions did not fall under the scope of the preceding EU public procurement directives of 2004 at all. For whatever reason, service-concessions were considered to be of secondary importance relative to worksconcessions.

The new public procurement code follows the EU Directives by regulating work- and serviceconcessions uniformly. However, instead of the detailed requirements for the award of contracts, less strict requirements apply. Firstly, the threshold before service concessions must be put out to tender across Europe is also significantly higher than for service contracts (5,548 million euros). And secondly, although a notice for concessions that exceed this threshold must be published, there is no formal award procedure (such as an open procedure, restricted procedure or competitive procedure with negotiations). National legislatures are given ample scope in this regard.

The Austrian legislature decided not to introduce further provisions regarding concessions and limited itself to implementing the provisions of the Directives. Concessions below certain thresholds in particular remain mostly unregulated. For example, the publication of an award notice is not mandatory if there is no clear cross-border interest. ${ }^{11}$ Thus, the changes for contracting authorities when awarding a concession are quite small. The biggest change concerns remedies. Previously, the award of service-concessions did not fall under the scope of remedies provided by public procurement law: any irregularities had to be brought before civil courts. In the future, decisions regarding the award of service-concessions - as of work-concessions - can be challenged before administrative

\footnotetext{
${ }^{9}$ ECJ 9.6.2009, C-480/06, Stadtreinigung Hamburg; 19.12.2012, C-159/11, Lecce; 16.5.2013, C-564/11, Lombardia; 13.6.2013, C-386/11, Piepenbrock.

${ }^{10}$ Art 10 Par 3 BVergG 2018.

${ }^{11}$ Art 22 Par 3 BVergGK 2018.
} 
courts, which has numerous benefits for applicants (especially the short duration of proceedings). ${ }^{12}$ Thus, we expect the number of court decisions regarding service-concessions to rise.

Service concessions for the supply of drinking water, however, do not fall under the scope of the directives or the public procurement act. Even if they did, the public procurement act would not oblige contracting authorities to privatize the drinking water supply but only regulates the procedure to do so, if contracting authorities decide to do so. Thus, there is no danger - and has never been of the Austrian government being forced to privatize the drinking water supply.

\section{Uniform rules for the award of services}

Another field of public procurement law, which has reputedly been harmonized by the Directives, is the award of service contracts. Until now, service contracts were divided into "Annex A" and "Annex B" services. While Annex A-services were subject to the full scope of public procurement law, significantly fewer rules applied to the award of Annex B-services. Annex B-services did not have to be awarded based on a formal award procedure and even publishing an award notice was not always compulsory. ${ }^{13}$

The Directives do not distinguish between Annex A and Annex B services. But not all services will be subject to the full scope of the directive in the future. Many of the services categorized as Annex $\mathrm{B}$ are now assigned to the "social and other specific services"-category. ${ }^{14}$ Simplified rules will continue to apply to such services. Whilst "normal" service contracts worth more than EUR 221,000 usually require an EU-wide tender notice to be published, authorities only need to publish an EUwide award notice about these special services when their value exceeds EUR 750,000.15

Further, special services need not be awarded within the standardized procedure laid down in the public procurement code. The contracting authority is given a relatively free hand to design the award procedure themselves. The Austrian legislature has also extended the ability to award such contracts directly. While "normal" services may be awarded directly up to an order value of EUR 50,000, the limit for special services has been doubled to EUR 100,000. ${ }^{16}$ Thus, the two-tier division of services has not been abolished, just redesigned.

\section{Passenger transport services}

The new public procurement code gives special treatment to the award of passenger transport services by rail and by road. Contracting authorities may use simplified procedures awarding these services. The provisions laid down in the code for passenger transport are similar to those concerning social and other specific services. ${ }^{17}$ However, remedies based on public procurement law will not be applicable to those procurement procedures from now on. ${ }^{18}$ This is a major drawback for those seeking effective remedies.

\section{E-procurement}

Small contracting authorities, especially municipalities, have viewed the upcoming mandatory use of electronic means of communication ("e-procurement") with some mistrust. The public procurement code requires - in line with the Directives - that electronic means must only be used for the essential elements of a procurement procedure, such as noticing and tender submission. ${ }^{19}$

\footnotetext{
12 Art 78 BVergGK 2018.

13 Art 141 Par 4 BVergG 2006.

14 Art 74 Dir 2014/24/EU and Annex XIV thereto.

${ }^{15}$ Art 12 BVergG 2018.

${ }^{16}$ Art 151 BVergG 2018.

${ }^{17}$ Art 151 BVergG 2018.

${ }^{18}$ Art 151 BVergG 2018.

${ }^{19}$ Art 48 BVergG 2018.
} 
Currently the public procurement code does not require public authorities to conduct all communication electronically. Contracting authorities do not necessarily have to use e-procurement platforms for the award of contracts.

Moreover, there is no requirement for the award of concessions to be handled via e-procurement and other contracts only require the use of e-procurement if their value exceeds the thresholds of the public procurement directives. ${ }^{20}$ Of course, it's already common practice to handle procurement procedures electronically for contracts above the thresholds. Two of the largest contracting authorities in Austria in particular have developed a shared e-procurement platform and have been using it for most of their award procedures for four years. Since the mandatory use of e-procurement only applies to contracts above the thresholds, small communities will hardly be affected by this requirement.

The law contains detailed provisions to ensure the equal treatment of tenderers and the security of data transmission. ${ }^{21}$ Exceptions are also foreseen, especially for cases where electronic means are hardly practical - for example, if large-format printers are needed or if plans or models have to be submitted, as is likely to be the case for architectural competitions. An exception is also made in those cases where data security cannot be guaranteed. We assume that this exception might be fulfilled in cases where cyber-attacks pose a threat.

The Austrian parliament has taken the chance to postpone the implementation of this requirement until 18 October 2018 except for central purchasing bodies. In Austria, one important central purchasing body has been established, the Bundesbeschaffung GmbH (BBG). This central purchasing body is often used by contracting authorities.

One of the main questions concerning e-procurement is whether the government will decide either that each contracting authority will have to use one centralized e-procurement platform or that each respective authority can decide for itself. Three main e-procurement platform operators have already established themselves. We doubt, therefore, that the government will opt for a centralized procurement platform.

\section{Changes regarding procurement procedures}

\subsection{Competitive procedure with negotiations, innovation partnership}

Initially, the European Commission planned to move away from standardized, mandatory procurement procedures and wanted to introduce a "toolbox" concept. However, this idea has been scrapped and the Directives present a final catalog of standardized procedural types. Nevertheless, the new procurement code introduces changes to procurement procedures: it now facilitates access to the negotiated procedure with prior notice and to the competitive dialogue in order to give contracting authorities more flexibility. ${ }^{22}$ Choosing the negotiated procedure or the competitive dialogue gives contracting authorities further the possibility to react to innovative proposals made by bidders, pick them up and adjust them within a certain range. Even though the competitive dialogue has not been used often in the past, there is a chance that its popularity among contracting authorities will rise in the future due to these amendments.

The public procurement act also establishes a new procedure, the innovation partnership. The innovation partnership is designed to enable contracting authorities to tender research and development services, and then subsequently to acquire the resulting product or service. ${ }^{23}$

\footnotetext{
${ }^{20}$ Art 48 BVergG 2018.

${ }^{21}$ Art 48 BVergG 2018.

${ }^{22}$ Art 34-37 BVergG 2018.

${ }^{23}$ Art 41 BVergG 2018.
} 
Although the services covered by this procedure are complex, the relevant provision of the Directives has been implemented. The Austrian legislation deviates from the Directives on this point and structures the public procurement act in a more user-friendly way. The aim of the innovation partnership is to select a private partner with whom to develop an innovative product, construction or service, which will ultimately be acquired by the client. ${ }^{24}$ In structuring the procurement process, the procuring entity is given a lot of flexibility. The coming years will show whether this procurement procedure will be used by contracting authorities.

\subsection{Preliminary market consultations, prior involvement of candidates}

In order to ensure the equal treatment of tenderers, the award-related activities of the contracting authority prior to the launch of the procurement procedure play an important role. This applies to market surveys on the client side as well as preliminary work by individual companies. As a result of transposing the Directives, the public procurement code expressly determines the conditions for the market research carried out in preparation for a procurement procedure for the first time.

If a company has been involved in preparing an award procedure or has advised the contracting authority, it must be excluded from the procurement competition unless it can prove that its involvement would not distort competition. In order to avoid distorting competition, the legislation compels the authority to comprehensively disclose all relevant information to all bidders. ${ }^{25}$

The legislation provides helpful guidelines and orientation for contracting authorities as well as private companies. ${ }^{26}$

\subsection{Prior information notices, division into lots}

Generally speaking, a procurement procedure must be initiated by publishing a prior notice about the contract to be awarded. Apart from that, contracts can be awarded directly, if their value is below EUR 100,000. ${ }^{27}$ So far, this has mostly been done by means of an award notice for each procurement procedure. From now on, contracting authorities may initiate a tender procedure by publishing a summarized prior information notice, which replaces the contract award notice. By choosing the summarized prior information notice, contracting authorities can bundle planned purchases within one publication notice. However, central contracting authorities are not allowed to use the summarized prior information notices. Moreover, the prior information notice may only be used for certain types of procedure, namely, the restricted and the competitive procedure with negotiation. ${ }^{28}$ If the prior information notice indicates that the award of the contract will take place without either subsequent publication or inviting companies to express their interest, then a separate contract award notice need not be published.

According to the public procurement act, contracts above the EU-thresholds shall be divided into lots in order to make it easier for small and medium sized enterprises (SME) to participate in such larger procurement procedures. However, the law does not state an obligation to do so; contracting authorities who decide not to divide a contract into lots are only obliged to give reasons for their decision in the documentation of the procedure or in the procurement documents themselves. ${ }^{29}$ Austria has a lot of SMEs and their competence and skills are widely acknowledged also among contracting authorities. Thus, it is common practice for contracting authorities to divide contracts

\footnotetext{
${ }^{24}$ Art 118-121 BVergG 2018.

${ }^{25}$ Art 25 BVergG 2018.

${ }^{26}$ Art 24-25 BVergG 2018.

${ }^{27}$ Art 46 BVergG 2018 limits a direct award to contracts below EUR 50,000. However, the Austrian government is entitled by Art 19 BVergG 2018 to increase this threshold. This has been done by a regulation, which will be in force until December $31^{\text {st }} 2020$.

${ }^{28}$ Art 57 BVergG 2018.

${ }^{29}$ Art 28 Par 6 BVergG 2018.
} 
into lots (wherever feasible) and for companies to bundle forces with other companies by participating as a consortium or as subcontractor.

\subsection{ESPD, "self-cleaning"}

According to the Directives, the European Single Procurement Document ("ESPD") will provide substantial relief for companies involved in cross-border applications. A company can fill out and submit the ESPD to confirm its suitability as a first step. The contracting authority is only obliged to verify the information given in the ESPD for the bidder they presume to be the best. This will save a considerable amount of examination time for the procuring entity and preparation time for the bidder. In Austria, however, the use of the ESPD is only mandatory for procurement procedures handling contracts above certain thresholds. ${ }^{30}$

Some have raised concerns about the user-friendliness of the ESPD. It is debatable whether it will be widely recognized or prove itself as helpful for bidders as it will for contracting authorities.

Following an Austrian Constitutional Court decision from 2002, a provision that allows a bidder to prove their suitability regardless of having fulfilled an exclusion ground (so called "self-cleaning"), has been introduced in the Austrian public procurement code. ${ }^{31}$ Art 57 Par 6 Dir 2014/24/EU resembles this provision to a large extent. However, there is a small change in the wording, which might lead to significant changes (and challenges) in practice.

Previously, the public procurement code listed example criteria that might be fulfilled in order to prove one's suitability. Those examples were regarded as alternatives that did not all have to be fulfilled and were linked by "or".

By contrast, the Directives - and thus the new public procurement code - lists the same criteria, but connects them with "and". Consequently, if a bidder now wants to successfully prove itself "clean", it has to prove that it has taken all the measures named in the public procurement code. This means

i. $\quad$ paying or undertaking to pay compensation for any damage caused by criminal offence or misconduct,

ii. clarifying the facts and circumstances in a comprehensive manner by actively collaborating with the investigating authorities, and

iii. taking the concrete technical, organizational and personnel measures that are appropriate to prevent further criminal offences or misconduct. ${ }^{32}$

Case Law will show how this provision is to be understood.

\subsection{Time limits, opening of tenders}

From now on, procurement procedures should take less time. In order to ensure this, the minimum periods to be granted by the procuring entity were considerably cut. For example the minimum time limit for the receipt of tenders within an open procedure is 30 days from the date on which the contract notice is sent. ${ }^{33}$ The minimum time limit for receipt of requests to participate within a restricted procedure is 30 days from the date on which the contract notice is sent. ${ }^{34}$ Nevertheless, the contracting authorities will also be interested in providing companies with sufficient time to prepare a well-worked-out offer in order to avoid problems.

\footnotetext{
${ }^{30}$ Art 80 Par 2 BVergG 2018.

${ }^{31}$ Art 73 BVergG 2006.

${ }^{32}$ Art 83 BVergG 2018.

${ }^{33}$ Art 71 BVergG 2018.

${ }^{34}$ Art 70 BVergG 2018.
} 
Previously, one of the main pillars of a procurement procedure from the bidder's viewpoint was the public opening of tenders. Within the transparent and fixed procedure, it was mandatory to open the tender in the presence of the bidders and to read out their essential contents, especially the prices offered by every bidder. ${ }^{35}$ The obligation to do this in front of the bidders has been withdrawn from the public procurement code. Given that electronic security measures must be used to prevent the premature or unauthorized opening of offers, withdrawing this obligation seems reasonable. A protocol regarding the opening of bids must be drawn up and sent to all tenderers to maintain transparency with regard to the prices offered..$^{36}$ However, without a public opening of tenders, bidders lose their chance to draw the procuring entity's attention to certain aspects of other bids that might influence the outcome of the procedure (e.g. the obvious lack of supplements).

\subsection{Changes regarding the MEAT-principle}

A previous change in public procurement procedure making the MEAT-principle ("most economically advantageous tender") mandatory in certain cases attracted a huge amount of publicity because it ensured the quality of the services or goods awarded. However, the scope of this provision was unclear, which limited its use. ${ }^{37}$ The new public procurement code defines such cases in a new and clearer way.

The application of the MEAT-principle is now mandatory in the following cases:

- if services are awarded within a competitive procedure with negotiations,

- if the services (their main parts) are described in a functional way,

- for works contracts with a value of more than EUR 1 million,

- for cleaning and security services,

- when awarded within a competitive dialogue or an innovation partnership. ${ }^{38}$

It is no longer explicitly stipulated by law that the MEAT-principle has to be applied if variants are allowed. Thus, as a general rule bidder are entitled to submit such tenders in procurement procedures. However, even though they meet the minimum qualitative requirements, variants often offer a qualitatively different technical solution that can only be reasonably assessed by using appropriate quality criteria in order to wage offers with different level of quality. We assume that in the case that variants are possible, the MEAT-principle has to be applied although not explicitly set out in the public procurement act.

The adjustments in the new public procurement code are not only clearly worded, but the content is also easily comprehensible.

\section{Changes to contracts during their term}

Of great practical importance is the question of whether lawfully awarded contracts can still be modified during their term. Changes to contractual obligations might be required, for example, because the actual soil conditions deviate from the assumed quality, or because the contractor declares bankruptcy (as the large construction company Alpine did some years ago). There are a number of cases in which amendments to the contract are necessary during their term. The relevant principles developed by ECJ were previously not codified, but it was understood that any changes in the contract after its award, for whatever reason, were only possible within limits.

\footnotetext{
${ }^{35}$ Art 118 BVergG 2018.

${ }^{36}$ Art 133 BVergG 2018.

${ }^{37}$ Art 79 BVergG 2006.

${ }^{38}$ Art 91 BVergG 2018.
} 
The new public procurement code sets out the criteria for lawful changes to contracts during their term in line with the Directives. ${ }^{39}$ However, the Austrian legislature has also incorporated the rulings made by the ECJ in the time since the directives were finalized. This especially concerns the judgment on Finn Frogne, which dealt with the question of whether a reduction of the contract's volume constitutes a substantial change and, therefore, cannot be made.

The public procurement act clarifies that not only the extension but also the reduction of a contract is unlawful if the volume of the contract is altered substantially. ${ }^{40}$

\section{Remedies}

The time limits for applying for review were previously different (shorter) for contracts below the EU-thresholds in Austria. ${ }^{41}$ The public procurement code now unifies the time limits so that regardless of the contract's value, the time limits set out in Dir 89/665/EEC apply. ${ }^{42}$

A significant change has also been made concerning the time limits for initiating a review procedure to investigate the ineffectiveness of an awarded contract (Art 2d Dir 89/665/EEC). The time limit for initiating such a review procedure was previously limited to six months after the conclusion of the contract, whether or not it had been possible for the applicant to have been informed about the conclusion of the contract. ${ }^{43}$ Since a successful review was required to gain compensation for damages, the ECJ held this time limit to be unlawful.

According to the new public procurement code, there is no general time limit for applying for such a review procedure after the conclusion of the contract. ${ }^{44}$ But if the application is filed more than six months after the conclusion of the contract, the review body can no longer declare the contract to be ineffective; it can only impose a fine on the contracting authority and/or declare that the award was unlawful. ${ }^{45}$ The current rules still lead to significant uncertainties for contracting authorities because fines of up to $20 \%$ of the contract's value might be imposed without any general time limit.

\section{Summary}

The new public procurement code creates legal certainty for both contracting authorities and contractors in several different aspects. However, the interpretation of some provisions will be subject to case law, especially regarding contractual cooperation between contracting authorities.

Some provisions of the Directives were restructured by the Austrian legislature, for example the newly introduced procurement procedure for innovation partnerships. Whether the idea of improving the readability and comprehensibility of this provision will lead to its increased use is open to question.

The Austrian legislature also responded to recent ECJ case law that was established after the EU Directives were published. For example, the question of whether a contract's volume may be lawfully reduced during its term is not addressed by the Directives. The Austrian legislator however has in light of the ECJ's ruling on Finn Frogne - clarified that significant reductions or extensions of a contract are not allowed by public procurement law.

\footnotetext{
${ }^{39}$ Art 365 BVergG 2018.

${ }^{40}$ Art 365 Par 2 BVergG 2018.

${ }^{41}$ Art 321 BVergG 2006.

${ }^{42}$ Art 343 BVergG 2006.

${ }^{43}$ Art 332 BVergG 2018.

${ }^{44}$ Art 354 BVergG 2018.

${ }^{45}$ Art 356 BVergG 2018.
} 
Concerning contracts not fully regulated by the Directives - such as concessions as well as social and other specific services - the Austrian legislature opted not to regulate them further and leave some flexibility to the contracting authorities.

To summarize, the Directives already set out a fairly concrete legal framework for national parliaments regarding public procurement procedures for work, supply and service contracts above certain thresholds. The Austrian parliament decided to implement these directives mostly word for word, but at the same time tried to preserve most of the historical developments to the public procurement law that were specific to Austria. 